\title{
Biological effects of inorganic phosphate: potential signal of toxicity
}

\author{
Seong-Ho Hong ${ }^{1, *}$, Sung-Jin Park ${ }^{1, *}$, Somin Lee ${ }^{1,3}$, Sanghwa Kim ${ }^{1,3}$ \\ and Myung-Haing Cho ${ }^{1,2,3,4}$ \\ ${ }^{1}$ Laboratory of Toxicology, BK21 PLUS Program for Creative Veterinary Science Research, Research Institute for \\ Veterinary Science and College of Veterinary Medicine, Seoul National University, Seoul 151-742, Korea \\ ${ }^{2}$ Graduate School of Convergence Science and Technology, Seoul National University, Suwon 443-270, Korea \\ ${ }^{3}$ Graduate Group of Tumor Biology, Seoul National University, Seoul 151-742, Korea \\ ${ }^{4}$ Advanced Institute of Convergence Technology, Seoul National University, Suwon 443-270, Korea
}

(Received October 6, 2014; Accepted December 3, 2014)

\begin{abstract}
Inorganic phosphate (Pi) plays crucial roles in several biological processes and signaling pathways. Pi uptake is regulated by sodium-dependent phosphate $(\mathrm{Na} / \mathrm{Pi})$ transporters $(\mathrm{NPTs})$. Moreover, $\mathrm{Pi}$ is used as a food additive in food items such as sausages, crackers, dairy products, and beverages. However, the high serum concentration of phosphate $(>5.5 \mathrm{mg} / \mathrm{dL})$ can cause adverse renal effects, cardiovascular effects including vascular or valvular calcification, and stimulate bone resorption. In addition, Pi can also alter vital cellular signaling, related to cell growth and cap-dependent protein translation. Moreover, intake of dietary $\mathrm{Pi}$, whether high $(1.0 \%)$ or low $(0.1 \%)$, affects organs in developing mice, and is related to tumorigenesis in mice. The recommended dietary allowance (RDA) of Pi is the daily dietary intake required to maintain levels above the lower limit of the range of normal serum Pi concentration $(2.7 \mathrm{mg} / \mathrm{dL})$ for most individuals $(97-98 \%)$. Thus, adequate intake of Pi (RDA; $700 \mathrm{mg} / \mathrm{day})$ and maintenance of normal Pi concentration $(2.7-4.5 \mathrm{mg} / \mathrm{dL})$ are important for health and prevention of diseases caused by inadequate Pi intake.
\end{abstract}

Key words: Inorganic phosphate toxicity, Sodium-dependent phosphate co-transporters, Tumorigenesis, Organ toxicity

\section{INTRODUCTION}

Inorganic phosphate (Pi) is an important component of DNA, RNA, cellular membrane phospholipids, and cellsignaling intermediates (Takeda et al., 2004). Pi is a vital nutrient in skeletal development, energy and metabolic processes. In addition, it is an essential element of gluconeogenesis and glycolysis. Under various physiological conditions, such as lactation and growth, the bodily requirements of phosphate are greater than those under normal conditions. To meet the additional physiological demands, which include the maintenance of total body phosphate homeostasis and the coordination of the kidneys and intestines. Particularly, the phosphate concentration and homeostasis primarily depend on tubular phosphate transport in the kidneys, at the membrane of the renal tubular brush border (Takeda et al., 2000).
In humans, the estimated average requirement (EAR) of $\mathrm{Pi}$ is $580 \mathrm{mg} /$ day, which is the value required to maintain the serum Pi concentration above the lower limit (about $2.7 \mathrm{mg} / \mathrm{dL}$ ) of the normal range $(2.7-4.5 \mathrm{mg} / \mathrm{dL})$. However, the EAR is a reliable indicator in only 50 percent of individuals. The RDA of Pi is $700 \mathrm{mg}$ /day, which is the sufficient dietary intake value to meet the requirements of nearly $97-98 \%$ of individuals. The tolerable upper intake level (UL) of Pi is 3,000-4,000 mg/day, which is the highest allowable value of daily intake with no adverse effect in any individual. An intake of about $3,400 \mathrm{mg} /$ day represents the upper limit (about $4.5 \mathrm{mg} / \mathrm{dL}$ ) of the normal range of serum Pi (Institute of Medicine, 1997). Therefore, we can set a low dietary phosphate content that is lower than the EAR. Moreover, high dietary phosphate concentrations could be set higher than the UL in healthy humans.

Correspondence: Myung-Haing Cho (E-mail: mchotox@snu.ac.kr)

*These authors equally contributed to this work. 


\section{S.-H. Hong et al.}

In the case of mice and rats, $0.5 \%$ phosphate in their diet is the criteria for normal dietary Pi concentration. High (1\%) dietary phosphate elevates the calcium concentration in kidneys, and induces histologic changes (Haut et al., 1980). A high (1.2\%) or low Pi (0.02\%) diet, can have influence on the NPT2 activity and protein expression at the membrane of the brush border (Katai et al., 1997).

Pi uptake is mediated by apical sodium-dependent phosphate $(\mathrm{Na} / \mathrm{Pi})$ co-transporters (NPT1, NPT2, and NPT3). NPT1 (NaPi-I, SLC17A1) is expressed in the human kidney, liver, brain, small intestine, or skeletal muscle, but not in the heart (Miyamoto et al., 1995). NPT1 may play a role in Pi transport or as a regulator of intrinsic activity (Bröer et al., 1998). NPT2 (NaPi-II) is related to renal Pi reabsorption and Pi controlling hormones (Takeda et al., 2000). Furthermore, the NPT2 transporter has three isoforms, NPT2a, NPT2b, and NPT2c.

NPT2a (NaPi-IIa, SLC34A1) is expressed in the renal proximal tubular cells, and is an important element to the renal reabsorption of $\mathrm{Pi}$ that is regulated by hormones and the diet (Tenenhouse, 2005). Low dietary Pi (0.1\%) intake increases the activity of the $\mathrm{Na} / \mathrm{Pi}$ co-transporter in the brush border membranes of the renal proximal tubule. By contrast, high dietary Pi (1.2\%) intake induces the internalization of NPT2a into endosomes (Lötscher et al., 1997). Invaginated NPT2a proteins are degraded via the proteolytic pathway, and are inhibited by lysosomal inhibitors (Pfister et al., 1998). The parathyroid hormone (PTH) can also inhibit Na/Pi co-transport via the modification of the protein expression of the $\mathrm{Na} / \mathrm{Pi}$ co-transporter (Kempson et al., 1995).

NPT2b (NaPi-IIb, SLC34A2) is expressed at the enterocyte brush borders of the small intestine, colon, apical membrane of alveolar type II cells, liver, kidneys, and testes (Hilfiker et al., 1998; Traebert et al., 1999). The NPT2b expression and the absorption of Pi by the intestinal brush-border membrane are inversely proportional to the age of an individual. In addition, 1,25- $(\mathrm{OH})_{2}$ vitamin $\mathrm{D}_{3}$ increases the NPT2b expression which is inhibited by actinomycin D (Xu et al., 2002).

NPT2c (NaPi-IIc, SLC34A3) has also been detected in the renal proximal tubular cells of the apical membrane. Moreover, a low Pi $(0.02 \%)$ diet increases NPT2c expression, whereas a high $\mathrm{Pi}(1.2 \%)$ diet induces the redistribution of the NPT2c protein, from the apical to the dense membrane in a microtubule-dependent manner (Segawa et al., 2005). The NPT3 co-transporters GLVR-1 (PiT-1, SLC20A1) and RAM-1 (PiT2, SLC20A2) are widely expressed in various organs, except in the spleen.
GLVR-1 shows the highest expression level in the heart, and RAM-1 displays the highest expression in the bone marrow. In addition, the overexpression of GLVR-1 and RAM-1 increases the transport of phosphate (Kavanaugh et al., 1994).

The consumption and the application of phosphate in food additives have been increasing in recent times (Calvo and Uribarri, 2013). The respective phosphate contents of each of these food items are described as follows: sausages (200-300 mg/150 g), processed cheese (400$500 \mathrm{mg} / 50 \mathrm{~g})$, whole-wheat bread $(100-200 \mathrm{mg} / 100 \mathrm{~g})$, and chocolate $(100-200 \mathrm{mg} / 50 \mathrm{~g})$. Even cola, beer, and fruit juice contain 50-100 mg phosphate per $200 \mathrm{~mL}$ (Ritz et al., 2012).

Various forms of phosphate are widely used as food additives. Sodium tripolyphosphate (STPP) is used in ham, bacon and sausages, for the maintenance of hydration and the structure form of the meat (Lampila, 2013). Phosphates are also applied to the chemical leavening of crackers and crispy cookies, as an acid in the reaction with sodium bicarbonate, to produce $\mathrm{CO}_{2}, \mathrm{H}_{2} \mathrm{O}$, and neutral salt (Brose et al., 1996). In addition, phosphates are used in dairy products, such as cheese and milk protein, for acidification or gelation (Ellinger, 1972). Sodium acid pyrophosphate (SAPP) is used in fruits and vegetables, to prevent "darkening" following cooking (Smith and Davis, 1962). Moreover, phosphoric acid is used in soft drinks as a flavoring agent (Lampila, 2013).

However, the dietary intake of phosphate additives can cause several diseases. Phosphate additives induce vascular damages, such as vascular calcification and advanced chronic kidney disease (CKD) (Ritz et al., 2012). The elevation of serum phosphate levels is related to the risk of mortality in CKD patients (Kestenbaum et al., 2005). Phosphates can also cause toxic effects related to aging, such as atrophy, fertility loss, and lifespan reduction (Ohnishi and Razzaque, 2010). Moreover, Pi can also control cell growth and cap-dependent translation (Chang et al., 2006).

In this review, we focus on the diseases and the toxic effects related to $\mathrm{Pi}$, and on solutions to each associated symptom. We also categorized the adverse effects of $\mathrm{Pi}$ intake by disease type.

\section{RENAL EFFECTS OF Pi}

\section{Renal effects of $\mathrm{Pi}$ in humans}

High dietary phosphate intake increases the serum and urinary phosphorus levels, as well as the excretion of hydroxyproline and cyclic adenosine monophosphate (cAMP). By contrast, the serum and urinary calcium 
Inadequate inorganic phosphate has potential toxicological effects

levels decline following a further increase in phosphate intake (Bell et al., 1977). High dietary Pi intake via food additives can critically affect patients with renal diseases, especially those patients with end-stage renal disease (ESRD) (Sullivan et al., 2009).

The high serum phosphate levels induced by a high Pi consumption also increases the risk of mortality in hemodialysis patients. More specifically, an average serum phosphate level $>6.5 \mathrm{mg} / \mathrm{dL}(2.10 \mathrm{mmol} / \mathrm{L})$ is significantly increases the mortality risk in hemodialysis patients. However, an average serum phosphate level lower than $6.5 \mathrm{mg} / \mathrm{dL}$ does not significantly increase the mortality risk (Rodriguez-Benot et al., 2005). In addition, a calcium $\times$ phosphate product greater than $72 \mathrm{mg}^{2} / \mathrm{dL}^{2}$ significantly increases the mortality risk in ESRD patients (Block et al., 1998). Changes in mineral metabolism, such as hyperphosphatemia and secondary hyperparathyroidism, have been reported in patients with cardiovascular diseases and hemodialysis (Block et al., 2004).

\section{Renal effects of $\mathrm{Pi}$ in animals}

In animal studies, a high (5 or $10 \%$ of inorganic phosphate in the diet) Pi intake can also cause damage to normal kidneys. In toxicological studies, oral administration of $\mathrm{Pi}$ at a high concentration (5 or 10\%) for two years caused renal calcification, increased kidney weight ratio, and various renal effects. It also caused lesions such as dilated convoluted tubules, disseminated tubular atrophy, focal scar tissue, fibrotic glomeruli, hyaline casts, inflammatory cell infiltration, interstitial fibrosis, and intertubular calcification (Weiner et al., 2001). Extent of these lesions can be exacerbated as the renal functional mass is reduced, due to nephrectomy (Haut et al., 1980).

\section{Conclusion of $\mathrm{Pi}$ on renal effects}

Taken together, these results suggest that optimal intake of $\mathrm{Pi}$ is strongly recommended not only for patients with renal diseases, but also for individuals with healthy kidneys. In particular, limiting the intake of dietary phosphate in food additives is strongly suggested for renal disease patients. The restriction of dietary phosphate additives effectively results in a reduction of the phosphorus levels in ESRD patients (Sullivan et al., 2009). Therefore, intensive educational programs and legal restrictions should be established to prevent the exacerbation of kidney disease (Uribarri, 2006).

\section{CARDIOVASCULAR EFFECTS OF Pi}

\section{Cardiovascular effects of $\mathrm{Pi}$ in humans}

Higher concentrations of serum phosphorus signifi- cantly increase the risk of cardiovascular disease, regardless of pre-existing CKD or cardiovascular disease (Dhingra et al., 2007). Moreover, increased serum phosphate concentrations are associated with thickening of the carotid intima-media, and represent a strong contributing factor to arteriosclerosis in hemodialysis patients (Ishimura et al., 2005). It also increases the risk factors of coronary artery atherosclerosis in young healthy adults. Specifically, the phosphate level is closely associated with the calcium level in coronary arteries (Foley et al., 2009).

Vascular smooth muscle cell calcification is regulated by phosphate. Human aortic smooth muscle cells (HSMC) show calcium deposition following treatment with high levels of $\mathrm{Pi}(>1.4 \mathrm{mmol} / \mathrm{L})$. High concentrations of phosphate increase the expression of osteocalcin, an osteoblastic differentiation marker. Moreover, these effects of phosphate are mediated by sodium-dependent phosphate ( $\mathrm{Na} / \mathrm{Pi}$ ) co-transporters (Jono et al., 2000).

In addition, hyperphosphatemia is related to aortic valve calcification in uremic patients. High serum phosphate levels can result in coronary plaque and affect arterial elasticity. They can also increase the risk of heart problems in patients with uremia, due to the decrease in arterial elasticity (Amann et al., 1999). Higher serum phosphate levels are associated with a higher incidence of calcification of the coronary artery, the aortic valve, the mitral valve and the descending thoracic aorta in patients of moderate CKD (Adeney et al., 2009).

\section{Conclusion of $\mathrm{Pi}$ on cardiovascular effects}

In summary, high serum phosphate levels can increase the risk of cardiovascular disease in patients with problems in cardiac or renal function. Moreover, a high phosphate diet also affects the risk of calcification in healthy individuals. Abnormal levels of serum phosphorus (>5.5 mg/dL), PTH, and calcium-phosphorus product (> $40 \%$ ) are strongly associated with calcification (Block and Port, 2000). Therefore, a strict restriction of the dietary Pi intake is very important not only for patients with diseases, but also for healthy individuals, to proactively prevent cardiovascular diseases.

\section{INFLUENCE OF Pi ON BONE RESORPTION}

\section{Influence of $\mathrm{Pi}$ on bone resorption in humans}

In healthy premenopausal women, the consumption of high levels of dietary phosphate additives resulted in lower serum calcium concentrations and in higher serum PTH concentrations than those found in the group consuming only natural phosphorus (Kemi et al., 2009). In children, drinking high amounts of soft drinks contain- 


\section{S.-H. Hong et al.}

ing phosphoric acid was found to be closely related to the development of hypocalcemia (Mazariegos-Ramos et al., 1995). Furthermore, compared to women who did not consume any beverages, the excessive consumption of soft drinks containing phosphoric acid by postmenopausal women caused hypocalcemia and increased the PTH serum levels (Fernando et al., 1999). High phosphate intake also decreases the levels of a bone formation marker, bone-specific alkaline phosphatase. It also increases the levels of the bone resorption marker N-terminal type I collagen telopeptide (Kemi et al., 2006).

Moreover, secondary hyperparathyroidism occurs following mild depression of blood calcium levels induced by high dietary phosphorus, which directly stimulates parathyroid activity (Sie et al., 1974). In this scenario, the synthesis and secretion of PTH is also increased. Both in human and in animals, the PTH levels increased following oral administration of phosphorus (Reiss et al., 1970; Laflamme and Jowsey, 1972). However, hypocalcemia induced by high dietary phosphate was not observed in parathyroidectomized rats. This result suggests that the activation of bone resorption by high phosphate levels is mediated mainly by the parathyroid gland (Anderson and Draper, 1972).

\section{Influence of $\mathrm{Pi}$ on bone resorption in animals}

A diet high in phosphate (1.2\% Pi for 16 months), fed long-term to nine-month-old mice, resulted in significantly reduced ash and calcium content, compared to mice that were fed a $0.6 \% \mathrm{Pi}$ diet. The bone-breaking load was also significantly reduced in the experimental mice. These phenomena could be ameliorated by reducing the Pi content of the diet from $1.2 \%$ to $0.6 \%$ (Krishnarao and Draper, 1972).

High (1.2\%) intake of Pi increases calcium excretion, due to the excess of Pi in the blood. In a six-month dietary phosphate experiment on seven-month-old SpragueDawley rats, calcium excretion increased by $16 \%$ and $37 \%$ in the $0.6 \%$ and $1.2 \%$ dietary Pi groups, respectively, compared to that of the $0.3 \%$ dietary Pi control group. In addition, the respective calcium contents of femurs, mandibles, and lumbar vertebrae were significantly decreased (Draper et al., 1972). High phosphate (1.2\% and 1.8\%) intake limits bone growth and increases the number of osteoclasts, and also reduces bone stiffness and toughness in the femoral neck and tibial shaft (Huttunen et al., 2007).

Furthermore, soft drinks containing phosphoric acid affected the calcium levels of immature Sprague-Dawley rats more strongly than those of young adult rats. The calcium levels of immature rats that had consumed soft drinks were significantly decreased compared to young adult rats (Amato et al., 1998). Ten-month-old female C57BL/6 mice that had been fed a diet of $1.2 \%$ calcium and $0.6 \% \mathrm{Pi}(\mathrm{Ca}: \mathrm{P}=2: 1)$ showed the best ash content, cortical thickness and breaking load, respectively. By contrast, mice fed a diet of $1.2 \%$ calcium and $1.2 \% \mathrm{Pi}$ $(\mathrm{Ca}: \mathrm{P}=1: 1)$ showed the lowest values for parameters related to the mineral content of bones (Shah et al., 1967).

\section{Conclusion of $\mathrm{Pi}$ on bone resorption}

Therefore, an adequate amount of $\mathrm{Pi}$, as well as an adequate ratio of $\mathrm{Pi}$ and calcium, is critical to the maintenance of healthy bones and to the prevention of osteoporosis. Further research and statistical analyses are required in animals and in clinical settings, to determine the ideal Pi intake based on an individual's age and gender (Sax, 2001).

\section{INFLUENCE OF Pi ON THE POSTNATAL ORGAN DEVELOPMENT IN YOUNG ANIMALS}

\section{Brain}

Sodium-dependent phosphate transporters in the brain

The Pi balance in the brain is also regulated by sodium-dependent phosphate co-transporters. The sodiumdependent Pi co-transporter is highly expressed in the human brain. The cerebral cortex and the hippocampus show a high expression of hBNPI. Moreover, the adult human brain displays a higher mRNA expression of human brain $\mathrm{Na}^{+}$-dependent inorganic phosphate cotransporter (hBNPI) than the fetal brain (Ni et al., 1996).

In addition, PiT2 (SLC2OA2), one of the NPT3 sodium-dependent phosphate transporters, is widely expressed in the brain. In particular, PiT2 is also detected in the endothelial cells and in the astrocytes. Therefore, PiT2 might play a crucial role in the regulation of $\mathrm{Pi}$ in these cells (Inden et al., 2013). In addition, the SLC20A2 mutation is also associated with idiopathic basal ganglia calcification (IBGC), better known as Fahr's disease (Wang et al., 2012). NPT2a is not localized in the mouse brain (Larsson et al., 2011).

\section{Influence of Pi on the postnatal brain development in young animals}

Adequate Pi intake is vital for the maintenance of health and of normal organs in young animals. Jin et al. (2006) administered high Pi (1.0\%) concentrations to two-week-old male mice for 4 weeks and then the mice were sacrificed at 6 weeks of age. This resulted in a reduction of their body weight and of the relative cere- 
Inadequate inorganic phosphate has potential toxicological effects

brum and cerebellum weight. High Pi doses also affected Akt1 phosphorylation, and thereby Akt activation. The level of phosphorylated Akt1 on Thr308 was decreased in the cerebellum in the group that reveived a high $\mathrm{Pi}$ dose. By contrast, the phosphorylation of Akt1 on Ser473 was increased in both the cerebrum and the cerebellum (Fig. 1A). Moreover, high dietary Pi intake affected AktERK signalings and cap-dependent translation. Furthermore, it also decreased the expression of proteins associated with cell proliferation. Therefore, high phosphate $(1.0 \%)$ levels can also have negative effects on brain development and lead to neurodegenerative diseases (Jin et al., 2006).

A low dose of Pi (0.144\%) administration experiment was also performed, to investigate the influence of dietary phosphate on the cerebrum of two-week-old male mice for 4 weeks. The administration of low Pi doses affected the expression levels of phosphatase and the tensin homolog deleted on chromosome 10 (PTEN) and Akt1. Low dietary Pi intake also suppressed the cap-dependent protein translation and the progression of the cell cycle. Furthermore, apoptosis was induced through the activation of Bad and caspase 3 proteins, in mice fed a low Pi diet compared to those fed a normal Pi diet $(0.5 \%)$. Apoptosis was also confirmed using a TUNEL assay (Fig. 1B). Therefore, adequate $\mathrm{Pi}$ intake is crucial to the normal brain development, especially at a young age (Jin et al., 2008).

\section{Lung}

Sodium-dependent phosphate transporters in the lungs

The Pi balance in the lungs is also regulated by sodium-phosphate transporter. NPT2b (SLC34A2) is highly expressed in the lungs, kidneys, and small intestine $(\mathrm{Xu}$ et al., 1999).

\section{Influence of Pi on postnatal lung development in young animals}

High dietary Pi (1.0\%) was administered to two-weekold mice for 4 weeks. The administration of a high Pi diet increased the phosphorylation of Akt1, both on Ser473 and Thr308. It also increased cap-dependent protein translation in the lungs through an increase in the phosphorylated form of 4E-BP1 (Fig. 2A) (Jin et al., 2007). 4E-BP1 represses mRNA translation, and is inactivated through phosphorylation by the Akt signaling pathway (Gingras et al., 1998). Moreover, a high dietary Pi intake increases proliferation, angiogenesis and cell cycle progression. Consequently, a high Pi intake can cause abnormal lung development, through disorders of the cell cycle and of cell proliferation (Jin et al., 2007).

$\mathrm{Xu}$ et al. (2009) administered low doses of $\mathrm{Pi}(0.1 \%)$ to two-week-old mice for 4 weeks. Low dietary Pi intake $(0.1 \%)$ also influences the development of lungs in young animals, by increasing pulmonary Akt1 phosphorylation at Ser473. In addition, low Pi administration stimulat-
A.
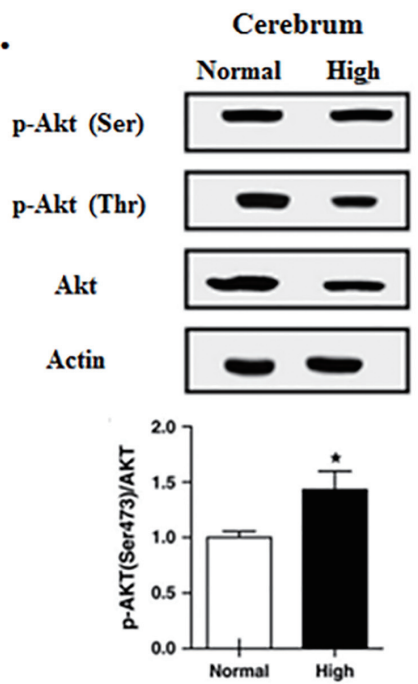

\section{Cerebellum}
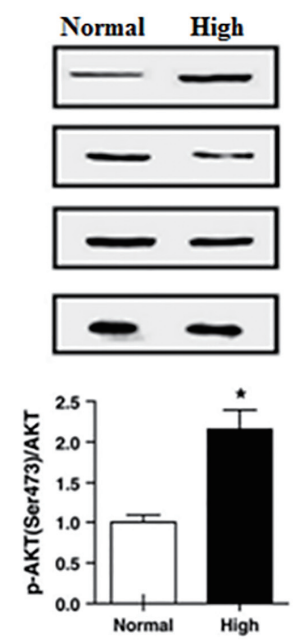

B.
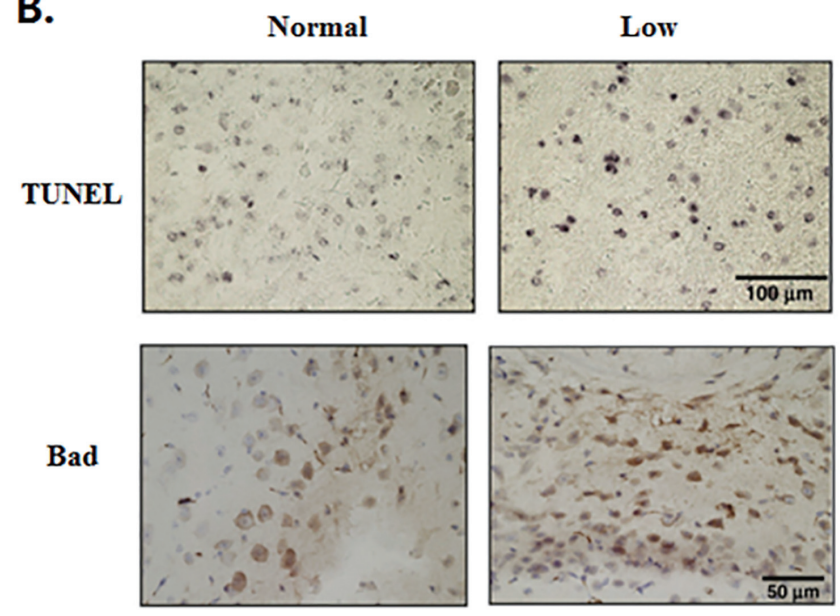

Fig. 1. Influence of inadequate inorganic phosphate ( $\mathrm{Pi}$ ) on the brains in developing animals (6 weeks after birth). (A) Expression of Akt and phospho-Akt in the brains of developing mice fed normal $(0.5 \%)$ or high $(1.0 \%)$ phosphate diet for 4 weeks. $* p<0.05$ statistically compared with normal group $(\mathrm{n}=5)$. Reproduced from reference (Jin et al., 2006) with permission. (B) TUNEL and immunohistochemistry (IHC) of Bad protein for detection of apoptotic signal in the cerebrum of developing mice fed normal $(0.5 \%)$ or low $(0.144 \%)$ diet for 4 weeks. Reproduced from reference (Jin et al., 2008) with permission. 

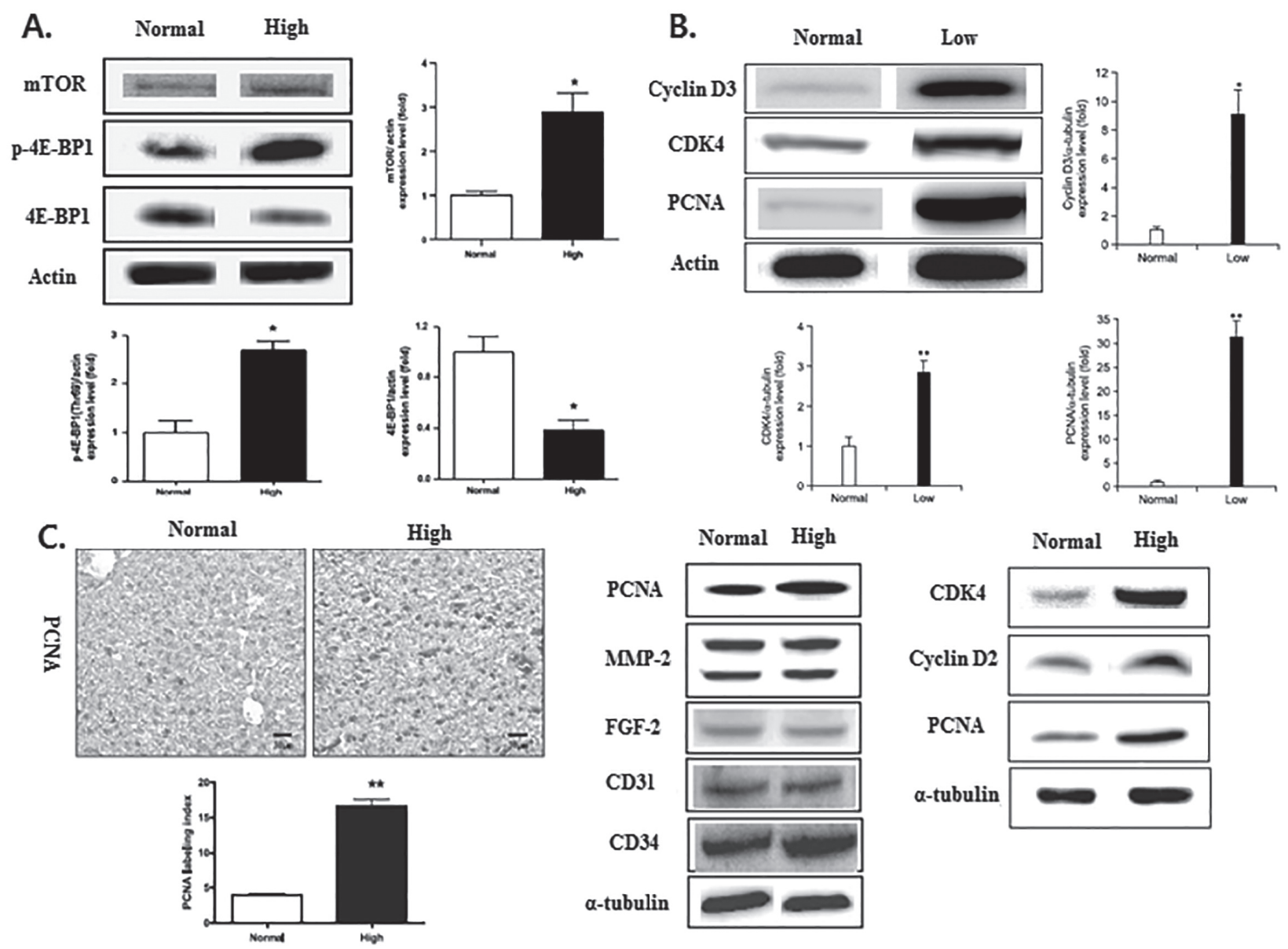

Fig. 2. Influence of inadequate inorganic phosphate (Pi) on the lungs and livers in developing animals (6-week-old after birth). (A) Expressions of mTOR and p-4E-BP1 in the lungs of developing mice fed normal $(0.5 \%)$ or high $(1.0 \%)$ phosphate diet for 4 weeks. ${ }^{*} p<0.05$ statistically compared with normal group $(\mathrm{n}=3)$. Reproduced from reference (Jin et al., 2007) with permission. (B) Expressions of Cyclin D3, CDK4 and PCNA in the lungs of developing mice fed normal $(0.5 \%)$ or low (0.1\%) phosphate diet for 4 weeks. $* * p<0.01$ and $* p<0.05$ statistically compared with normal group $(\mathrm{n}=4)$. Reproduced from reference (Xu et al., 2009) with permission. (C) IHC of PCNA and Western blot of PCNA, MMP-2, FGF-2, CD31, CD34, CDK4 and Cyclin D2 in the livers of developing mice fed normal $(0.5 \%)$ or high $(1.0 \%)$ phosphate diet for 2 or 4 weeks. $* * p<0.01$ statistically compared with normal group. Reproduced from reference (Xu et al., 2008) with permission.

ed cap-dependent translation, proliferation and cell cycle progression, compared to administration of normal $\mathrm{Pi}$ $(0.5 \%)$ diet (Fig. 2B). Consequently, low Pi intake could negatively affect lung development or predispose to pulmonary diseases at a young age in mice. Thus, appropriate $\mathrm{Pi}$ intake is necessary to maintain healthy lungs and for normal lung development in young mice (Xu et al., 2009).

\section{Liver}

Sodium-dependent phosphate transporters in the liver

The transport and concentration of $\mathrm{Pi}$ in hepatocytes are also regulated by sodium-phosphate co-transporters. The
NPT2b, PiT-1 and PiT-2 co-transporters are expressed in the rat liver. NPT2b is detected in the canalicular plasma membrane of the rat liver, but not in the basolateral membrane. NPT2b is also detected in the brush-border membrane of cholangiocytes in the interlobular bile ducts. By contrast, PiT-1 and PiT-2 are detected in the basolateral liver plasma membrane (Frei et al., 2005).

\section{Influence of Pi on postnatal liver development in young animals}

$\mathrm{Xu}$ et al. (2008) administered high doses of dietary Pi (1.0\%) to two-week-old mice for 2 weeks. High Pi doses increase the relative liver weight to body weight 
Inadequate inorganic phosphate has potential toxicological effects

ratio and cap-dependent protein translation. A consumption of high amounts of Pi affects Akt1 phosphorylation, both at Thr308 and Ser473. Moreover, it also elevates cell cycle progression, proliferation, and angiogenesis (Fig. 2C). Therefore, an adequate ingestion of $\mathrm{Pi}$ is essential for normal liver development (Xu et al., 2008).

\section{HORMONAL REGULATION OF PI AND INFLUENCE ON AGING AND FERTILITY}

Pi homeostasis is regulated by various hormones and organ reabsorption. The serum levels of phosphate and calcium are maintained by bone reabsorption, intestinal absorption, and urine or fecal excretion (Berndt and Kumar, 2009). Pi absorption in the intestine is regulated by $1,25(\mathrm{OH})_{2} \mathrm{D}_{3}$, at a rate of $1-1.5 \mathrm{~g}$ per $24 \mathrm{hr}$. Renal Pi excretion is mainly stimulated by PTH at the proximal straight and convoluted tubules (Berndt and Kumar, 2007).

\section{FGF23}

The levels of fibroblast growth factor-23 (FGF23) are related to phosphate regulation. FGF23 is released from the bones when the serum phosphate level exceeds normal levels. This inhibits the synthesis of vitamin D, and triggers the excretion of phosphorus through the kidneys, to maintain phosphate homeostasis (Quarles, 2003). A FGF23 missense mutation is associated with the autosomal dominant form of hypophosphatemic rickets (ADHR). High serum levels of FGF23 and bone mineralization defects (phosphate-wasting) are evident in ADHR, as the mutated region is critical to the resistance to proteolytic degradation of FGF23 (White et al., 2000).

FGF23 knockout $\left(\mathrm{Fg} f \mathrm{3}^{-/}\right)$mice displayed hyperphosphatemia and calcification of the soft tissues (phosphate retention), and showed higher serum levels of calcium and PTH than wild-type mice. These knockout mice also presented increased serum $1,25(\mathrm{OH})_{2} \mathrm{D}_{3}$ levels, through high expression of renal 25-hydroxyvitamin D-1 $\alpha$ hydroxylase (1 $\alpha$-OHase). In addition, FGF23-null mice displayed retarded growth and a short lifespan (no more than 13 weeks). Moreover, they showed reduced mineralization and bone development. Increased serum levels of blood urea nitrogen (BUN), glomeruli atrophy and calcification of the kidneys have also been reported in FGF23 knockout mice (Shimada et al., 2004).

\section{Klotho}

Klotho is a transmembrane protein and an aging-suppressor that acts as an essential co-factor in the binding of FGF23 and the FGF receptor. It is also associat- ed with calcium reabsorption and phosphate homeostasis. Down-regulation of Klotho is associated with the development of aging-like syndrome (Kuro-o, 2006). A defect in the Klotho gene $(k l / k l)$, induced by transgene insertional mutation in mice, resulted in a retarded growth rate, a shorter lifespan (no longer than 100 days), hypokinesis and abnormal walking disturbances. Impaired gametocyte maturation and atrophy of the skin, the testes, the ovaries, the uterus, and the thymus, respectively, are phenotypes of $k l / k l$ mice. Moreover, it has been shown that osteoporosis, ectopic calcification, abnormalities in the pituitary gland, and emphysema are also induced over a period of time. Furthermore, mice with a defect in the Klotho gene showed elevated serum levels of phosphorus and calcium (Kuro-o et al., 1997).

\section{NaPi2a knockout mice}

By contrast, a NaPi2a-knockout strain developed hypophosphatemia and an abnormal change in skeletal development. NaPi2a-knockout mice weaned at 21 days of age showed developmental defects in the metaphyseal trabeculae and improper ossification phenotypes, compared to wild-type mice. However, 115-day-old $\mathrm{NaPi} 2 \mathrm{a}^{-/-}$mice displayed reversely overcompensated bone phenotypes. In addition, more epiphyseal bone marrow is calcified in NaPi2a-knockout mice (Beck et al., 1998). Moreover, $\mathrm{NaPi2a}$-knockout mice showed increased bone formation, surfaces of osteoblasts, and mineralization with decreasing osteoclast numbers (Gupta et al., 2001).

\section{Aging-like syndrome}

$\mathrm{NaPi}^{2-/}$ and $\mathrm{Klotho}^{-/-}$double-knockout mice showed remission of aging-like syndrome and of ectopic calcification. This strain showed increased bodyweight and lifespan, compared to Klotho-knockout mice. Moreover, the phosphate levels and fertility were normal in the double-knockout mice. Furthermore, vascular calcification and atrophy of the skin, muscle, intestine, and gonadal tissues were absent in this strain. Interestingly, these ameliorated aging-like phenotypes were reversibly exacerbated by high dietary phosphate (1.2\% phosphorus) fed to $\mathrm{NaPi2a^{-/ }}$ and $\mathrm{klotho}^{-/-}$mice. The lifespan was significantly reduced and organ atrophies were noted, in double-knockout mice having received high phosphate doses, as uncontrolled access to Pi induced a toxic response. In addition, this group of mice showed infertility, calcification, and kyphosis (Ohnishi and Razzaque, 2010; Kuro-o, 2010).

Consequently, defects in the expression of phosphateregulating proteins (FGF-23 and Klotho) caused hyperphosphatemia. These genetic ablations of phosphate 


\section{S.-H. Hong et al.}

related hormones displayed aging-like syndromes such as atrophy of genital organs and osteoporosis, as well as a short life-span. Meanwhile, the double-knockout of $\mathrm{NaPi2} a$ and Klotho ameliorated this syndrome, but aging was eventually accelerated due to excessive phosphate supply. Thus, adequate phosphate intake as well as the knowledge of the respective roles of FGF23, Klotho and $\mathrm{NaPi2a}$ are crucial for the regulation of Pi homeostasis against aging.

\section{Influence of $\mathrm{Pi}$ on oxidative stress}

The phosphate concentration is also associated with an increase in the levels of reactive oxygen species (ROS). High levels of phosphate stimulate mitochondrial oxidative phosphorylation, causing an increase in ROS levels (Bose et al., 2003). In addition, Pi enhances mitochondrial permeability transition, leading to necrosis or apoptosis (Kowaltowski et al., 2001). Furthermore, oxidative stress over a long period causes DNA damage, cell cycle arrest, and cellular senescence (Chen et al., 2007).

\section{Influence of Pi concentration on fertility}

Moreover, some studies have reported that phosphate levels affect fertility. The above-mentioned Klotho knockout mice and NaPi2a/Klotho double-knockout mice that were fed a high phosphate (1.2\%) diet showed infertility and senescence (Ohnishi and Razzaque, 2010). In dairy cattle, the plasma Pi concentration could affect the non-return rates after mating (Hunter, 1977). In addition, improper concentrations of Pi in the luminal fluid of the cauda epididymis leads to problems in sperm maturation. Mice in which the receptor of the proto-oncogene c-ros tyrosine kinase was knocked out showed infertility due to defective sperm maturation and flagellar angulation (Yeung et al., 1999). Moreover, the knockout in these mice resulted in the expression of a differentially localized NaPi-IIb transporter, compared to that of heterozygous mice, which affected the Pi concentration and sperm maturation (Xu et al., 2003).

Consequently, the Pi concentration affects the mitochondria and triggers oxidative stress that could be associated with aging. Moreover, Pi also influences fertility. Therefore, homeostasis and regulation of $\mathrm{Pi}$ is important to lower oxidative stress and to promote anti-aging and fertility.

\section{INFLUENCE OF PI ON CELLULAR SIGNALING AND TUMORIGENESIS}

\section{Influence of Pi on cellular signaling and cancer}

Pi stimulates the phosphorylation of Aktl at Thr308 and downstream signaling pathways such as Raf/MEK/ ERK. Akt1 is an important serine/threonine kinase in the phosphatidylinositol3-kinase (PI3K) pathway, and it is involved in cell cycle and apoptosis. Akt regulates cancer cell proliferation through the inhibition of apoptosis (Lawlor and Alessi, 2001). The ERK pathway links extracellular signals to intracellular signals that activate cellular proliferation (Raman and Cobb, 2003).

Moreover, Pi activates the nuclear translocation of Mnk1, which sequentially increases cap-dependent protein translation through the phosphorylation of eIF4E-BP1 (Chang et al., 2006). Pi also stimulates the activity of the mammalian target of rapamycin (mTOR) protein kinase autophosphorylation at Ser-2481 (Wang et al., 2003). The activity of the kinase mTOR is also related to cellular growth, proliferation, transcription, and protein synthesis (Jacinto and Hall, 2003). Thus, the Pi levels might play crucial roles in cellular signaling pathways that mediate cellular growth and proliferation.

Some studies have reported that $\mathrm{Pi}$ is also associated with the promotion of angiogenesis and of tumor cell migration. In response to $\mathrm{Pi}$ treatment, the respective expression levels of forkhead box protein $\mathrm{C} 2$ (FOXC2), osteopontin (OPN), and vascular endothelial growth factor alpha (VEGF $\alpha$ ) increased (Lin et al., 2014). FOXC2, a transcription factor, is necessary for vascular development (Seo et al., 2006). OPN is involved in neoplastic transformation processes such as tumor invasion, migration, and metastasis (El-Tanani et al., 2006). OPN is also associated with angiogenesis that is necessary for tumor growth (Hirama et al., 2003). Signaling pathways that are activated by Pi also include the FGF receptor, guanosine triphosphate (GTP) signaling, FGF receptor substrate 2 (FRS2 $\alpha$ ) and ERK1/2 (Camalier et al., 2013). Consequently, $\mathrm{Pi}$ is involved in neoplastic cellular growth and vascular development.

Increased levels of Pi also activate signaling pathways involving the neuroblastoma RAS viral oncogene homolog (N-ras) (Camalier et al., 2010). Ras genes are oncogenes that are activated in cancer. $R A S$ genes are related to cellular responses such as proliferation, cell cycle and apoptosis (Malumbres and Pellicer, 1998). Moreover, in a mouse model of skin carcinogenesis, high doses of dietary phosphate (1.2\%) significantly enhanced the skin papilloma number through an increase in the circulating OPN levels (Camalier et al., 2010).

Based on the statistical results of clinical research, some cancer types showed a correlation between the serum levels of Pi and the risk of developing cancer. In comparison to lung, thyroid gland, and bone cancer in men, esophagus and non-melanoma skin cancer in wom- 
Inadequate inorganic phosphate has potential toxicological effects

en showed a positive correlation between Pi levels and the risk of developing cancer. However, cancers of the endocrine organs in both men and women, as well as breast and endometrium cancers, showed negative correlations between the levels of Pi and the risk of developing cancer (Wulaningsih et al., 2013).

Animal experiments have revealed the relationship between dietary phosphate and lung tumorigenesis. Jin et al. (2006) administered high doses of dietary Pi $(1.0 \%)$ to urethane-induced and $K-r a s^{\mathrm{LA} 1}$ lung cancer mice for 4 weeks. High dietary Pi intake (1.0\%) enhanced NPT2b protein expression, Akt activity, proliferation, and cap-dependent protein translation in the lungs through the suppression of a carboxyl-terminal modulator protein (CTMP) and PTEN, compared to normal dietary $\mathrm{Pi}(0.5 \%)$ intake. Moreover, high dietary phosphate intake facilitated lung tumorigenesis in both the urethaneinduced and $K-r a s^{\mathrm{LA} 1}$ lung cancer mouse models (Fig. 3A,
3B, 3C) (Jin et al., 2009).

Low dietary $\mathrm{Pi}(0.1 \%)$ intake also increases the expression of NPT2b in the lungs. Low dietary Pi was administered to five-week-old $K$-ras ${ }^{\mathrm{LA} 1}$ mice from the lung cancer model mentioned above for 4 weeks. Consumption of low Pi activates Akt signaling, cellular proliferation, translation, and the cell cycle while decreasing PTEN expression. It also exacerbates tumorigenesis in a mouse model of $K-r a s^{\mathrm{LA} 1}$ lung cancer (Fig. 3D, 3E, 3F) (Xu et $a l ., 2010)$. Therefore, adequate phosphate intake is necessary for the prevention of lung cancer.

\section{Relationship of the $\mathrm{Na} / \mathrm{Pi}$ co-transporter NPT2b with cancer}

Increased NPT2b (SLC34A2) expression was commonly observed in both the high and low phosphate intake groups in the animal dietary experiments mentioned above (Jin et al., 2009; Xu et al., 2010). NPT2b
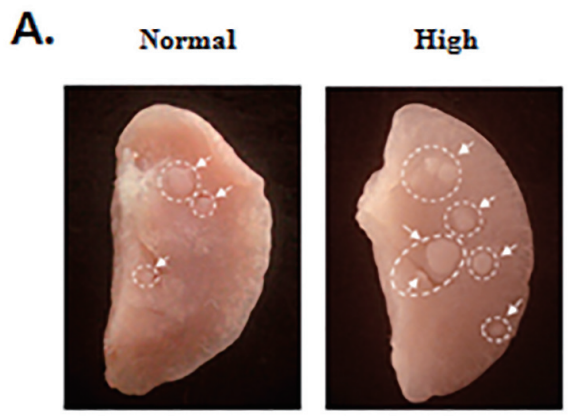

B.

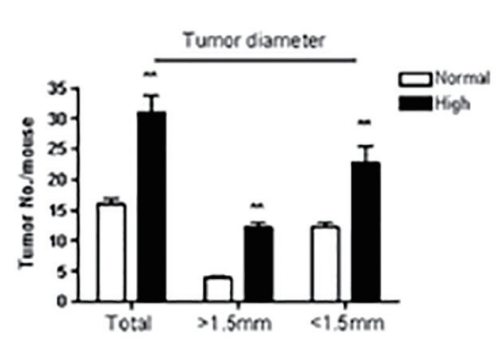

E.
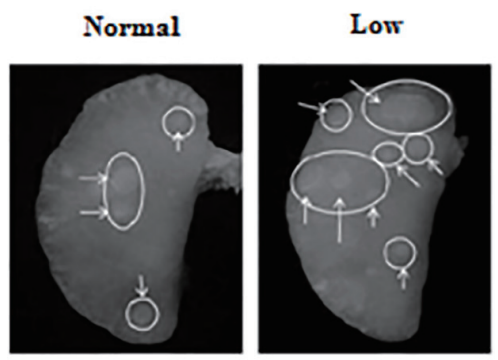

\section{E.}

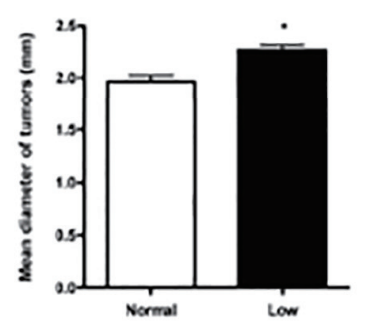

c.

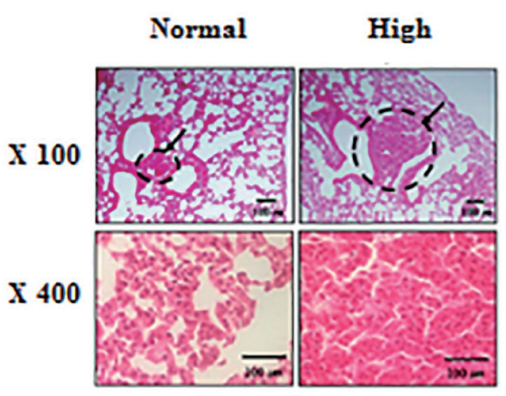

F.
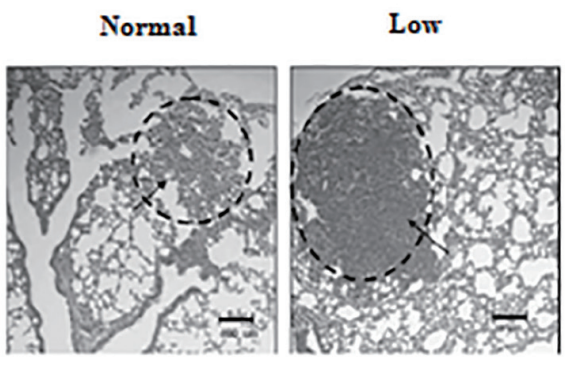

Fig. 3. Influence of inadequate inorganic phosphate (Pi) on the lung tumorigenesis in K-ras ${ }^{\mathrm{LA} 1}$ mice (9-week-old after birth). (A) Lung tumor lesions in K-ras ${ }^{\mathrm{LA} 1}$ mice fed normal $(0.5 \%)$ or High $(1.0 \%)$ phosphate diet for 4 weeks. (B) Number of tumor lesions on the lung surfaces. ${ }^{* *} p<0.01$ statistically compared with normal group $(\mathrm{n}=9)$. (C) Histopathology of lung tumors. Reproduced from reference (Jin et al., 2009) with permission. (D) Lung tumor lesions in K-ras ${ }^{\mathrm{LA} 1}$ mice fed normal $(0.5 \%)$ or Low $(0.1 \%)$ phosphate diet for 4 weeks. (E) Mean diameter of tumor lesions on the lung surfaces. $* p<0.05$ statistically compared with normal group $(\mathrm{n}=9)$. (F) Histopathology of lung tumor lesions. Reproduced from reference $(\mathrm{Xu}$ et al., 2010) with permission. 


\section{S.-H. Hong et al.}

might be a useful target for histopathology of the lung cancer and associated therapies (Hashimoto et al., 2000; Yin et al., 2008). In addition, NPT2b is overexpressed in ovarian cancer and is correlated with differentiation (Rangel et al., 2003). Moreover, NPT2b is highly expressed in the tissues of breast cancer and papillary thyroid cancer, compared to normal tissues (Chen et al., 2010; Kim et al., 2010).

Furthermore, NPT2b is overexpressed in the lungs of $K$-ras ${ }^{\mathrm{LA} 1}$ lung cancer mice, compared to wild-type mice. The mRNA levels of NPT2b were also high in human lung adenocarcinoma tissues, compared to normal tissues. For lung cancer therapy via knockdown of NPT2b, a complex of glycerol propoxylate triacrylate spermine (GPT$\mathrm{SPE}) / \mathrm{siNPT} 2 \mathrm{~b}$ ( $0.5 \mathrm{mg}$ of siRNA) complex was delivered in aerosol form to 10 -week-old $K$-ras ${ }^{\mathrm{LA} 1}$ mice from the lung cancer model mentioned above, twice a week for 4 weeks in a nose-only exposure chamber. Suppression of NPT2b expression significantly inhibited lung tumorigenesis via the induction of apoptosis in $K$-ras ${ }^{\mathrm{LA} 1}$ lung cancer model mice (Fig. 4). Consequently, the $\mathrm{Na} / \mathrm{Pi}$ co-transporter NPT2b is abnormally expressed in various cancers, and targeting phosphate transporter is effective for lung cancer therapy (Hong et al., 2013).

Pi plays an important role in cellular signaling, cell components, structure, energy supply, and metabolic processes. Pi uptake is mediated by sodium-dependent phosphate $(\mathrm{Na} / \mathrm{Pi})$ co-transporters. The use and consumption of $\mathrm{Pi}$ as a food additive has been increasing in food items such as bacon, sausages, cookies, dairy products, and beverages. However, phosphate additives can produce harmful effects on various organs, and thereby lead to many diseases. Furthermore, maintenance of normal Pi concentration is also important for optimal health.

Abnormal intake of Pi elevates the mortality risk due to renal diseases, especially in ERSD and hemodialysis patients. Specifically, high serum phosphate $(>6.5 \mathrm{mg} / \mathrm{dL}$ ) strongly increases the cardiovascular damages observed in patients with cardiac or renal problems. A high phosphate diet also influences bone resorption. High dietary phosphate intake decreases the calcium content of bones, mediated by PTH, in a phenomenon called secondary hyperparathyroidism. Appropriate amounts of phosphorus and calcium $(\mathrm{Ca}: \mathrm{P}=2: 1)$ are therefore essential for the prevention of osteoporosis.

High $(1.0 \%)$ or low $(0.1 \%)$ dietary Pi intakes have negative effects on the development of the brain, lungs and liver in mice, through modification of Akt activation, proliferation and cell cycle progression. However, the toxicological effects of Pi on neurodegenerative diseases have not been well studied either in humans or in animals. For example, in animals, behavior tests following the administration of long-term, high doses of Pi need to be performed for the verification of the potential neurodegenerative effects. Furthermore, the effects of a high or low dietary Pi intake on embryonic development, based on maternal Pi concentrations, have to be investigated to confirm potential toxicity.

Moreover, Pi affects pivotal genes in signaling pathways such as Akt, mTOR and Raf/MEK/ERK. Pi also stimulates tumorigenesis through the enhancement of proliferation and cap-dependent protein translation. In capdependent translation, the binding of eukaryotic translation initiation factor 4E (eIF4E) to the cap structure of messenger RNA is necessary for the initiation of translation. The control of translation is very important and associated with development, cancer, and nervous system (Richter and Sonenberg, 2005). Especially in cancer, unregulated cap-dependent translation stimulates tumor formation (Ruggero et al., 2004). Furthermore, the translation machinery is deregulated and over-expressed in cancer (Ruggero et al., 2003).

4E-BP1 inhibits translation and is inactivated via phosphorylation by growth signaling. Phosphorylated 4E-BP1 is detached from eIF4E, thereby initiating cap-dependent translation (Schmelzle et al., 2000). Moreover, the functional loss of 4E-BP1 stimulates the epithelial-mesenchymal transition (EMT) of cancer epithelial cells. In contrast, dephosphorylated 4E-BP1 inhibits the invasion and migration of cancer cells. Therefore, 4E-BP1 is an important regulator of cap-dependent translation and of cancer metastasis (Cai et al., 2014).

In effect, lung cancer, breast cancer, and endocrine organ cancer display a positive correlation with the $\mathrm{Pi}$ level and the risk of cancer in a human population-based study. In animal studies, high (1.0\%) or low $(0.1 \%)$ dietary phosphate increases the expression of NPT2b in the lungs. Taken together, these results suggest that the increase in translation caused by inadequate phosphate intake may promote oncogenic transformation, including lung tumorigenesis.

Various harmful effects of Pi were summarized as a brief figure in Fig. 5.

Meanwhile, we also need to determine how to compare animal toxicological data with data on human intake of Pi. To convert the animal data to a human equivalent dose (HED), we can consider the conversion of the Pi dose based on the body surface area (BSA), and not simply the body weight. When converting a rat dose to human intake, we have to consider the $K_{\mathrm{m}}$ factor, which is the value of body weight $(\mathrm{kg})$ divided by the BSA $\left(\mathrm{m}^{2}\right)$. For example, consider the human $K_{\mathrm{m}}$ factor is 37 (60 kg divid- 
Inadequate inorganic phosphate has potential toxicological effects

A.

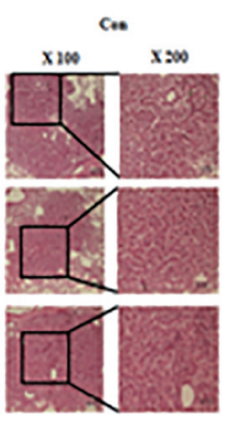

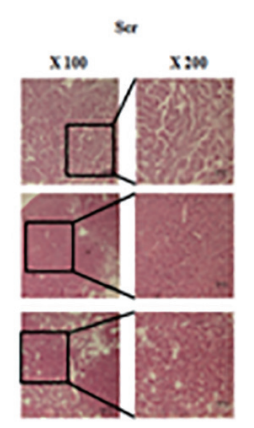

B.

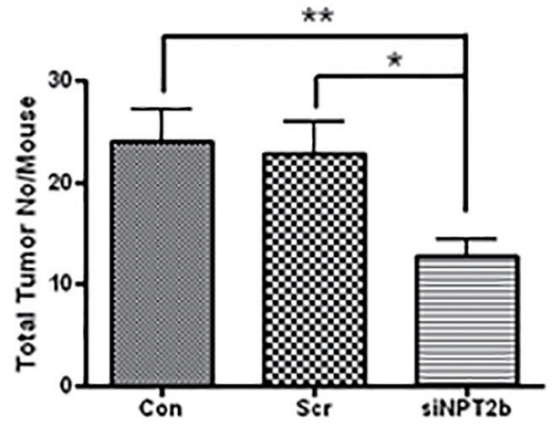

C.

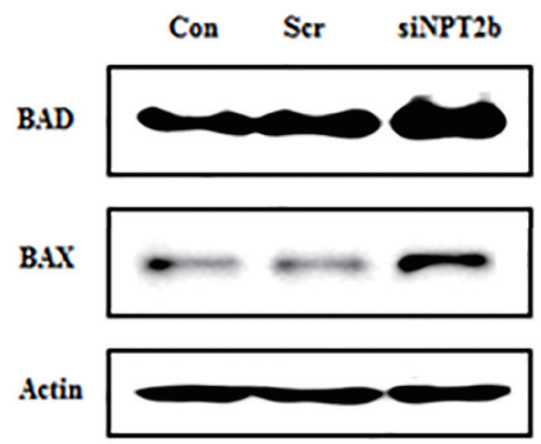

D.

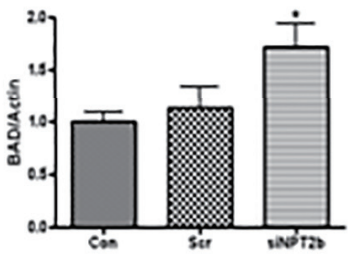

Fig. 4. Suppression of sodium-dependent phosphate co-transporter $2 b$ (NPT2b) inhibits lung tumor formation. (A) Histopathology of lung tumor lesions in Control (Con), small interfering RNA scramble (Scr) and small interfering RNA NPT2b (siNPT2b) delivered groups. (B) Total tumor number of Con, Scr and siNPT2b delivered groups. $* * p<0.01$ and $* p<0.05$ statistically compared with Con or Scr $(n=6)$. (C) Protein expressions of BAD and BAX proteins. (D) Densitometric analyses of BAD and BAX proteins. ${ }^{*} p<0.05$ statistically compared with Con or Scr $(\mathrm{n}=4)$. Reproduced from reference (Hong et al., 2013) with permission.

ed by $\left.1.6 \mathrm{~m}^{2}\right)$ and the $K_{\mathrm{m}}$ factor for the rat is $6(0.15 \mathrm{~kg}$ divided by $0.025 \mathrm{~m}^{2}$ ) (Reagan-Shaw et al., 2008). Therefore, we can approximately calculate the HED of Pi using the Pi dose in the rat multiplied by the rat $K_{\mathrm{m}}$ factor (6)/ human $K_{\mathrm{m}}$ factor (37).

In the case of rats, $0.5 \%$ dietary $\mathrm{Pi}$ approximates a human Pi dose of $250 \mathrm{mg} / \mathrm{kg} / \mathrm{day}$, which is a normal dietary Pi intake (Haut et al., 1980). According to calculation method above, a HED of $250 \mathrm{mg} / \mathrm{kg} /$ day (rat normal Pi diet) is about $40.54 \mathrm{mg} / \mathrm{kg} /$ day $(2,432 \mathrm{mg} /$ day for a $60 \mathrm{~kg}$ person). This Pi amount of 2,432 mg/day is slightly higher than the RDA. However, this value is between the RDA (700 mg/day) and the UL (3,000-4,000 mg/day) of $\mathrm{Pi}$ in humans. Moreover, $1.0 \%$ dietary $\mathrm{Pi}$ is approximately the same as $500 \mathrm{mg} / \mathrm{kg} / \mathrm{day}$, which is a high dietary Pi intake for rats (Haut et al., 1980). A HED of $500 \mathrm{mg} / \mathrm{kg} /$ day (high Pi diet for rat) is about $81.08 \mathrm{mg} / \mathrm{kg} /$ day $(4,864$ $\mathrm{mg} /$ day for a $60 \mathrm{~kg}$ person). This Pi amount of $4,864 \mathrm{mg} /$ day is much higher than the UL (3,000-4,000 mg/day) in human. Therefore, although the HED calculation from the rat dose based on the BSA cannot be directly applied to human intake, toxicological effects could be expected in humans based on these animal data.

In conclusion, an adequate intake of Pi is important for the prevention of diseases induced by inappropriate $\mathrm{Pi}$ intake. Specifically, patients with renal or cardiac diseases should be encouraged to restrict their dietary Pi intake through educational programs. Moreover, an adequate nutrient ratio of phosphorus and calcium should be met for healthy people to prevent osteoporosis. More research and analyses are required to determine the appropriate amount of phosphorus intake based on age, gender, and the presence of any disease. Furthermore, targeting genes encoding phosphate transporters represent a novel avenue 


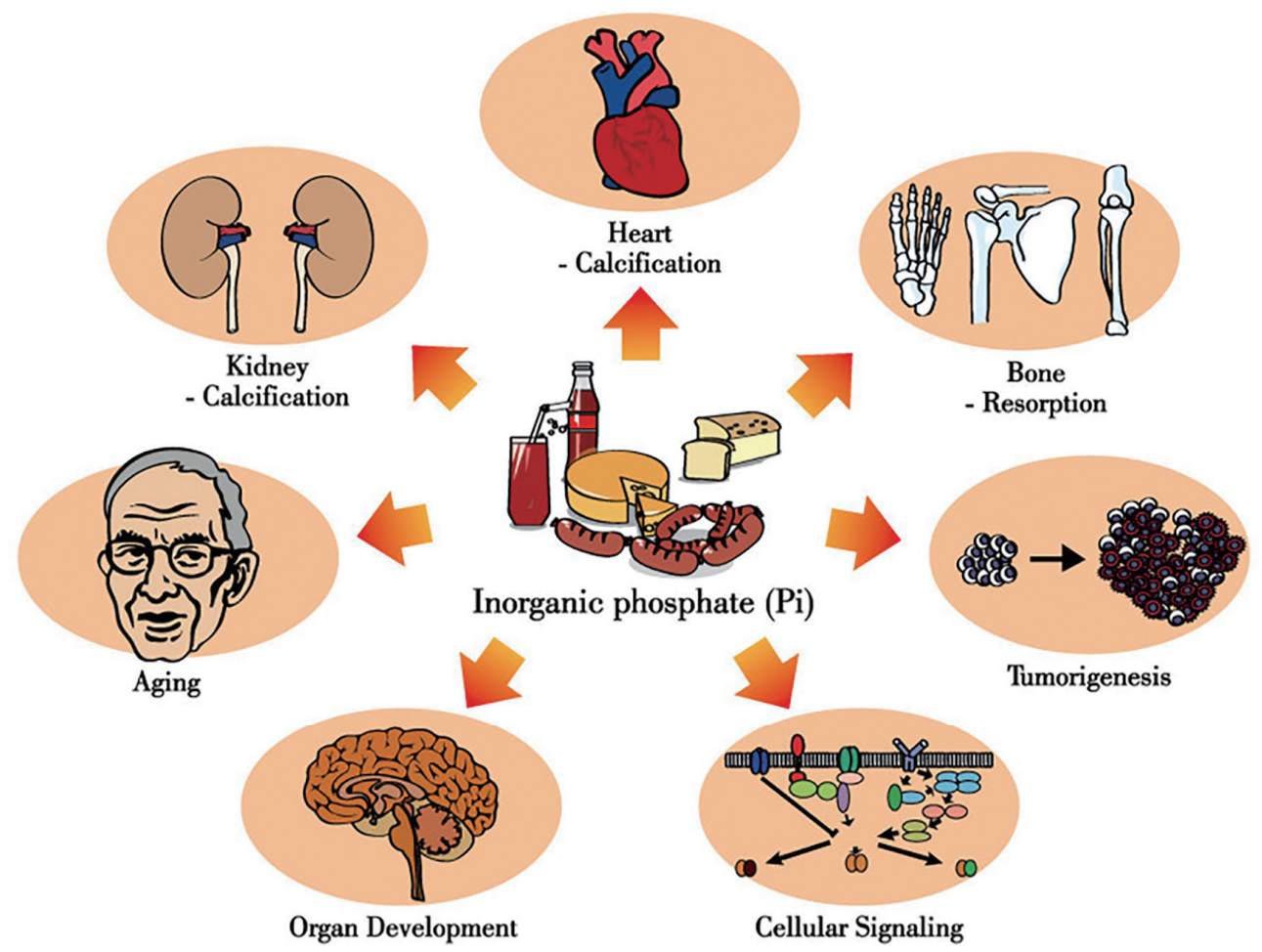

Fig. 5. Various side effects of inorganic phosphate as a food additive.

of cancer therapy.

Conflict of interest---- The authors declare that there is no conflict of interest.

\section{ACKNOWLEDGEMENTS}

This work was supported by the Bio-Synergy Research Project (NRF-2012M3A9C4048819) of the Ministry of Science, ICT and Future Planning through the National Research Foundation.

\section{REFERENCES}

Adeney, K.L., Siscovick, D.S., Ix, J.H., Seliger, S.L., Shlipak, M.G., Jenny, N.S. and Kestenbaum, B.R. (2009): Association of serum phosphate with vascular and valvular calcification in moderate CKD. J. Am. Soc. Nephrol., 20, 381-387.

Amann, K., Gross, M.L., London, G.M. and Ritz, E. (1999): Hyperphosphataemia--a silent killer of patients with renal failure? Nephrol. Dial. Transplant., 14, 2085-2087.

Amato, D., Maravilla, A., Montoya, C., Gaja, O., Revilla, C., Guerra, R. and Paniagua, R. (1998): Acute effects of soft drink intake on calcium and phosphate metabolism in immature and adult rats. Rev. Invest. Clin., 50, 185-189.
Anderson, G.H. and Draper, H.H. (1972): Effect of dietary phosphorus on calcium metabolism in intact and parathyroidectomized adult rats. J. Nutr., 102, 1123-1132.

Beck, L., Karaplis, A.C., Amizuka, N., Hewson, A.S., Ozawa, H. and Tenenhouse, H.S. (1998): Targeted inactivation of Npt2 in mice leads to severe renal phosphate wasting, hypercalciuria, and skeletal abnormalities. Proc. Natl. Acad. Sci. USA, 95, 5372-5377.

Bell, R.R., Draper, H.H., Tzeng, D.Y., Shin, H.K. and Schmidt, G.R. (1977): Physiological responses of human adults to foods containing phosphate additives. J. Nutr., 107, 42-50.

Berndt, T. and Kumar, R. (2007): Phosphatonins and the regulation of phosphate homeostasis. Annu. Rev. Physiol., 69, 341-359.

Berndt, T. and Kumar, R. (2009): Novel mechanisms in the regulation of phosphorus homeostasis. Physiology (Bethesda), 24, $17-25$.

Block, G.A., Hulbert-Shearon, T.E., Levin, N.W. and Port, F.K. (1998): Association of serum phosphorus and calcium x phosphate product with mortality risk in chronic hemodialysis patients: a national study. Am. J. Kidney Dis., 31, 607-617.

Block, G.A., Klassen, P.S., Lazarus, J.M., Ofsthun, N., Lowrie, E.G. and Chertow, G.M. (2004): Mineral metabolism, mortality, and morbidity in maintenance hemodialysis. J. Am. Soc. Nephrol., 15, 2208-2218.

Block, G.A. and Port, F.K. (2000): Re-evaluation of risks associated with hyperphosphatemia and hyperparathyroidism in dialysis patients: recommendations for a change in management. Am. J. Kidney Dis., 35, 1226-1237. 
Inadequate inorganic phosphate has potential toxicological effects

Bose, S., French, S., Evans, F.J., Joubert, F. and Balaban, R.S. (2003): Metabolic network control of oxidative phosphorylation: multiple roles of inorganic phosphate. J. Biol. Chem., 278, 39155-39165.

Bröer, S., Schuster, A., Wagner, C.A., Bröer, A., Forster, I., Biber, J., Murer, H., Werner, A., Lang, F. and Busch, A.E. (1998): Chloride conductance and $\mathrm{Pi}$ transport are separate functions induced by the expression of NaPi-1 in Xenopus oocytes. J. Membr. Biol., 164, 71-77.

Brose, E., Becker, G. and Bouchain, W. (1996): Chemical Leavening Agents. Chemische Fabrik Budenheim Rudolf A. Oetker. Budenheim, Germany.

Cai, W., Ye, Q. and She, Q.B. (2014): Loss of 4E-BP1 function induces EMT and promotes cancer cell migration and invasion via cap-dependent translational activation of snail. Oncotarget, 5, 6015-6027.

Calvo, M.S. and Uribarri, J. (2013): Public health impact of dietary phosphorus excess on bone and cardiovascular health in the general population. Am. J. Clin. Nutr., 98, 6-15.

Camalier, C.E., Yi, M., Yu, L.R., Hood, B.L., Conrads, K.A., Lee, Y.J., Lin, Y., Garneys, L.M., Bouloux, G.F., Young, M.R., Veenstra T.D., Stephens R.M., Colburn, N.H., Conrads, T.P. and Beck G.R.Jr. (2013): An integrated understanding of the physiological response to elevated extracellular phosphate. J. Cell. Physiol., 228, 1536-1550.

Camalier, C.E., Young, M.R., Bobe, G., Perella, C.M., Colburn, N.H. and Beck, G.R.Jr. (2010): Elevated phosphate activates $\mathrm{N}$-ras and promotes cell transformation and skin tumorigenesis. Cancer Prev. Res. (Phila), 3, 359-370.

Chang, S.H., Yu, K.N., Lee, Y.S., An, G.H., Beck, G.R.Jr., Colburn, N.H., Lee, K.H. and Cho, M.H. (2006): Elevated inorganic phosphate stimulates Akt-ERK1/2-Mnk1 signaling in human lung cells. Am. J. Respir. Cell Mol. Biol., 35, 528-539.

Chen, D.R., Chien, S.Y., Kuo, S.J., Teng, Y.H., Tsai, H.T., Kuo, J.H. and Chung, J.G. (2010): SLC34A2 as a novel marker for diagnosis and targeted therapy of breast cancer. Anticancer Res., 30, 4135-4140.

Chen, J.H., Ozanne, S.E. and Hales, C.N. (2007): Methods of cellular senescence induction using oxidative stress. Methods Mol. Biol., 371, 179-189.

Dhingra, R., Sullivan, L.M., Fox, C.S., Wang, T.J., D’Agostino, R.B.Sr., Gaziano, J.M. and Vasan, R.S. (2007): Relations of serum phosphorus and calcium levels to the incidence of cardiovascular disease in the community. Arch. Intern. Med., 167, 879885.

Draper, H.H., Sie, T.L. and Bergan, J.G. (1972): Osteoporosis in aging rats induced by high phosphorus diets. J. Nutr., 102, 11331141.

El-Tanani, M.K., Campbell, F.C., Kurisetty, V., Jin, D., McCann, M. and Rudland, P.S. (2006): The regulation and role of osteopontin in malignant transformation and cancer. Cytokine Growth Factor Rev., 17, 463-474.

Ellinger, R.H. (1972): Phosphates as food ingredients. CRC Press. Cleveland, $\mathrm{OH}$.

Fernando, G.R., Martha, R.M. and Evangelina, R. (1999): Consumption of soft drinks with phosphoric acid as a risk factor for the development of hypocalcemia in postmenopausal women. J. Clin. Epidemiol., 52, 1007-1010.

Foley, R.N., Collins, A.J., Herzog, C.A., Ishani, A. and Kalra, P.A. (2009): Serum phosphorus levels associate with coronary atherosclerosis in young adults. J. Am. Soc. Nephrol., 20, 397-404.

Frei, P., Gao, B., Hagenbuch, B., Mate, A., Biber, J., Murer, H.,
Meier, P.J. and Stieger, B. (2005): Identification and localization of sodium-phosphate cotransporters in hepatocytes and cholangiocytes of rat liver. Am. J. Physiol. Gastrointest. Liver Physiol., 288, G771-G778.

Gingras, A.C., Kennedy, S.G., O'Leary, M.A., Sonenberg, N. and Hay, N. (1998): 4E-BP1, a repressor of mRNA translation, is phosphorylated and inactivated by the Akt(PKB) signaling pathway. Genes Dev., 12, 502-513.

Gupta, A., Tenenhouse, H., Hoag, H., Wang, D., Khadeer, M., Namba, N., Feng, X. and Hruska, K. (2001): Identification of the type II $\mathrm{Na}(+)-\mathrm{Pi}$ cotransporter $(\mathrm{Npt} 2)$ in the osteoclast and the skeletal phenotype of Npt2-/- mice. Bone, 29, 467-476.

Hashimoto, M., Wang, D.Y., Kamo, T., Zhu, Y., Tsujiuchi, T., Konishi, Y., Tanaka, M. and Sugimura, H. (2000): Isolation and localization of type IIb $\mathrm{Na} / \mathrm{Pi}$ cotransporter in the developing rat lung. Am. J. Pathol., 157, 21-27.

Haut, L.L., Alfrey, A.C., Guggenheim, S., Buddington, B. and Schrier, N. (1980): Renal toxicity of phosphate in rats. Kidney Int., 17, 722-731.

Hilfiker, H., Hattenhauer, O., Traebert, M., Forster, I., Murer, H. and Biber, J. (1998): Characterization of a murine type II sodiumphosphate cotransporter expressed in mammalian small intestine. Proc. Natl. Acad. Sci. USA, 95, 14564-14569.

Hirama, M., Takahashi, F., Takahashi, K., Akutagawa, S., Shimizu, K., Soma, S., Shimanuki, Y., Nishio, K. and Fukuchi, Y. (2003): Osteopontin overproduced by tumor cells acts as a potent angiogenic factor contributing to tumor growth. Cancer Lett., 198, 107-117.

Hong, S.H., Minai-Tehrani, A., Chang, S.H., Jiang, H.L., Lee, S., Lee, A.Y., Seo, H.W., Chae, C., Beck, G.R.Jr. and Cho, M.H. (2013): Knockdown of the sodium-dependent phosphate cotransporter $2 \mathrm{~b}$ (NPT2b) suppresses lung tumorigenesis. PLoS One, 8, e77121.

Hunter, A. (1977): Some nutritional factors affecting the fertility of dairy cattle. N. Z. Vet. J., 25, 305-307.

Huttunen, M.M., Tillman, I., Viljakainen, H.T., Tuukkanen, J., Peng, Z., Pekkinen, M. and Lamberg-Allardt, C.J. (2007): High dietary phosphate intake reduces bone strength in the growing rat skeleton. J. Bone Miner. Res., 22, 83-92.

Inden, M., Iriyama, M., Takagi, M., Kaneko, M. and Hozumi, I. (2013): Localization of type-III sodium-dependent phosphate transporter 2 in the mouse brain. Brain Res., 1531, 75-83.

Institute of Medicine, F.A.N.B. (1997): Dietary reference intakes for calcium, phosphorus, magnesium, vitamin $\mathrm{D}$, and fluoride. Washington, DC: Natl. Acad. Press.

Ishimura, E., Taniwaki, H., Tabata, T., Tsujimoto, Y., Jono, S., Emoto, M., Shoji, T., Inaba, M., Inoue, T. and Nishizawa, Y. (2005): Cross-sectional association of serum phosphate with carotid intima-medial thickness in hemodialysis patients. Am. J. Kidney Dis., 45, 859-865.

Jacinto, E. and Hall, M.N. (2003): Tor signalling in bugs, brain and brawn. Nat. Rev. Mol. Cell Biol., 4, 117-126.

Jin, H., Chang, S.H., Xu, C.X., Shin, J.Y., Chung, Y.S., Park, S.J., Lee, Y.S., An, G.H., Lee, K.H. and Cho, M.H. (2007): High dietary inorganic phosphate affects lung through altering protein translation, cell cycle, and angiogenesis in developing mice. Toxicol. Sci., 100, 215-223.

Jin, H., Hwang, S.K., Kwon, J.T., Lee, Y.S., An, G.H., Lee, K.H., Prats, A.C., Morello, D., Beck, G.R.Jr. and Cho, M.H. (2008): Low dietary inorganic phosphate affects the brain by controlling apoptosis, cell cycle and protein translation. J. Nutr. Biochem., 19, 16-25. 
Jin, H., Hwang, S.K., Yu, K., Anderson, H.K., Lee, Y.S., Lee, K.H., Prats, A.C., Morello, D., Beck, G.R.Jr. and Cho, M.H. (2006): A high inorganic phosphate diet perturbs brain growth, alters AktERK signaling, and results in changes in cap-dependent translation. Toxicol. Sci., 90, 221-229.

Jin, H., Xu, C.X., Lim, H.T., Park, S.J., Shin, J.Y., Chung, Y.S., Park, S.C., Chang, S.H., Youn, H.J., Lee, K.H., Lee, Y.S., Ha, Y.C., Chae, C.H., Beck, G.R.Jr and Cho, M.H. (2009): High dietary inorganic phosphate increases lung tumorigenesis and alters Akt signaling. Am. J. Respir. Crit. Care Med., 179, 59-68.

Jono, S., McKee, M.D., Murry, C.E., Shioi, A., Nishizawa, Y., Mori, K., Morii, H. and Giachelli, C.M. (2000): Phosphate regulation of vascular smooth muscle cell calcification. Circ. Res., 87, E1017.

Katai, K., Segawa, H., Haga, H., Morita, K., Arai, H., Tatsumi, S., Taketani, Y., Miyamoto, K., Hisano, S., Fukui, Y. and Takeda E. (1997): Acute regulation by dietary phosphate of the sodium-dependent phosphate transporter $(\mathrm{NaP}(\mathrm{i})-2)$ in rat kidney. J. Biochem., 121, 50-55.

Kavanaugh, M.P., Miller, D.G., Zhang, W., Law, W., Kozak, S.L., Kabat, D. and Miller, A.D. (1994): Cell-surface receptors for gibbon ape leukemia virus and amphotropic murine retrovirus are inducible sodium-dependent phosphate symporters. Proc. Natl. Acad. Sci. USA, 91, 7071-7075.

Kemi, V.E., Kärkkäinen, M.U. and Lamberg-Allardt, C.J. (2006): High phosphorus intakes acutely and negatively affect $\mathrm{Ca}$ and bone metabolism in a dose-dependent manner in healthy young females. Br. J. Nutr., 96, 545-552.

Kemi, V.E., Rita, H.J., Kärkkäinen, M.U., Viljakainen, H.T., Laaksonen, M.M., Outila, T.A. and Lamberg-Allardt, C.J. (2009): Habitual high phosphorus intakes and foods with phosphate additives negatively affect serum parathyroid hormone concentration: a cross-sectional study on healthy premenopausal women. Public Health Nutr., 12, 1885-1892.

Kempson, S.A., Lötscher, M., Kaissling, B., Biber, J., Murer, H. and Levi, M. (1995): Parathyroid hormone action on phosphate transporter mRNA and protein in rat renal proximal tubules. Am. J. Physiol., 268, F784-791.

Kestenbaum, B., Sampson, J.N., Rudser, K.D., Patterson, D.J., Seliger, S.L., Young, B., Sherrard, D.J. and Andress, D.L. (2005): Serum phosphate levels and mortality risk among people with chronic kidney disease. J. Am. Soc. Nephrol., 16, 520-528.

Kim, H.S., Kim do, H., Kim, J.Y., Jeoung, N.H., Lee, I.K., Bong, J.G. and Jung, E.D. (2010): Microarray analysis of papillary thyroid cancers in Korean. Korean J. Intern. Med., 25, 399-407.

Kowaltowski, A.J., Castilho, R.F. and Vercesi, A.E. (2001): Mitochondrial permeability transition and oxidative stress. FEBS Lett., 495, 12-15.

Krishnarao, G.V. and Draper, H.H. (1972): Influence of dietary phosphate on bone resorption in senescent mice. J. Nutr., 102, $1143-1145$

Kuro-o, M. (2006): Klotho as a regulator of fibroblast growth factor signaling and phosphate/calcium metabolism. Curr. Opin. Nephrol. Hypertens., 15, 437-441.

Kuro-o, M. (2010): A potential link between phosphate and aginglessons from Klotho-deficient mice. Mech. Ageing Dev., 131, 270-275.

Kuro-o, M., Matsumura, Y., Aizawa, H., Kawaguchi, H., Suga, T., Utsugi, T., Ohyama, Y., Kurabayashi, M., Kaname, T. and Kume, E. (1997): Mutation of the mouse klotho gene leads to a syndrome resembling ageing. Nature, 390, 45-51.

Laflamme, G.H. and Jowsey, J. (1972): Bone and soft tissue chang- es with oral phosphate supplements. J. Clin. Invest., 51, 28342840.

Lampila, L.E. (2013): Applications and functions of food-grade phosphates. Ann. N Y. Acad. Sci., 1301, 37-44.

Larsson, M., Morland, C., Poblete-Naredo, I., Biber, J., Danbolt, N. C. and Gundersen, V. (2011): The Sodium-Dependent Inorganic Phosphate Transporter SLC34A1 (NaPi-IIa) Is Not Localized in the Mouse Brain A Case of Tissue-Specific Antigenic Cross-Reactivity. J. Histochem. Cytochem., 59, 807-812.

Lawlor, M.A. and Alessi, D.R. (2001): PKB/Akt: a key mediator of cell proliferation, survival and insulin responses? J. Cell Sci., 114, 2903-2910.

Lin, Y., McKinnon, K.E., Ha, S.W. and Beck, G.R.Jr. (2014): Inorganic phosphate induces cancer cell mediated angiogenesis dependent on forkhead box protein $\mathrm{C} 2$ (FOXC2) regulated osteopontin expression. Mol. Carcinog., Epub ahead of print.

Lötscher, M., Kaissling, B., Biber, J., Murer, H. and Levi, M. (1997): Role of microtubules in the rapid regulation of renal phosphate transport in response to acute alterations in dietary phosphate content. J. Clin. Invest., 99, 1302-1312.

Malumbres, M. and Pellicer, A. (1998): RAS pathways to cell cycle control and cell transformation. Front. Biosci., 3, d887-912.

Mazariegos-Ramos, E., Guerrero-Romero, F., Rodríguez-Morán, M., Lazcano-Burciaga, G., Paniagua, R. and Amato, D. (1995): Consumption of soft drinks with phosphoric acid as a risk factor for the development of hypocalcemia in children: a case-control study. J. Pediatr., 126, 940-942.

Miyamoto, K., Tatsumi, S., Sonoda, T., Yamamoto, H., Minami, H., Taketani, Y. and Takeda, E. (1995): Cloning and functional expression of a $\mathrm{Na}(+)$-dependent phosphate co-transporter from human kidney: cDNA cloning and functional expression. Biochem. J., 305, 81-85.

Ni, B., Du, Y., Wu, X., DeHoff, B.S., Rosteck, P.R. and Paul, S.M. (1996): Molecular cloning, expression, and chromosomal localization of a human brain-specific $\mathrm{Na}^{+}$-dependent inorganic phosphate cotransporter. J. Neurochem., 66, 2227-2238.

Ohnishi, M. and Razzaque, M.S. (2010): Dietary and genetic evidence for phosphate toxicity accelerating mammalian aging. FASEB J., 24, 3562-3571.

Pfister, M.F., Hilfiker, H., Forgo, J., Lederer, E., Biber, J. and Murer, H. (1998): Cellular mechanisms involved in the acute adaptation of $\mathrm{OK}$ cell $\mathrm{Na} / \mathrm{Pi}$-cotransport to high- or low-Pi medium. Pflugers Arch., 435, 713-719.

Quarles, L.D. (2003): FGF23, PHEX, and MEPE regulation of phosphate homeostasis and skeletal mineralization. Am. J. Physiol. Endocrinol. Metab., 285, E1-9.

Raman, M. and Cobb, M.H. (2003): MAP kinase modules: many roads home. Curr. Biol., 13, R886-888.

Rangel, L.B., Sherman-Baust, C.A., Wernyj, R.P., Schwartz, D.R., Cho, K.R. and Morin, P.J. (2003): Characterization of novel human ovarian cancer-specific transcripts (HOSTs) identified by serial analysis of gene expression. Oncogene, 22, 7225-7232.

Reagan-Shaw, S., Nihal, M. and Ahmad, N. (2008): Dose translation from animal to human studies revisited. FASEB. J., 22, 659661.

Reiss, E., Canterbury, J.M., Bercovitz, M.A. and Kaplan, E.L. (1970): The role of phosphate in the secretion of parathyroid hormone in man. J. Clin. Invest., 49, 2146-2149.

Richter, J.D. and Sonenberg, N. (2005): Regulation of cap-dependent translation by eIF4E inhibitory proteins. Nature, 433, $477-$ 480.

Ritz, E., Hahn, K., Ketteler, M., Kuhlmann, M.K. and Mann, 
Inadequate inorganic phosphate has potential toxicological effects

J. (2012): Phosphate additives in food--a health risk. Dtsch. Arztebl. Int., 109, 49-55.

Rodriguez-Benot, A., Martin-Malo, A., Alvarez-Lara, M.A., Rodriguez, M. and Aljama, P. (2005): Mild hyperphosphatemia and mortality in hemodialysis patients. Am. J. Kidney Dis., 46, 68-77.

Ruggero, D., Montanaro, L., Ma, L., Xu, W., Londei, P., CordonCardo, C. and Pandolfi, P.P. (2004): The translation factor eIF$4 \mathrm{E}$ promotes tumor formation and cooperates with c-Myc in lymphomagenesis. Nat. Med., 10, 484-486.

Ruggero, D., Pandolfi, P.P. Does the ribosome translate cancer? (2003): Does the ribosome translate cancer? Nat. Rev. Cancer, 3, 179-192.

Sax, L. (2001): The institute of medicine's "dietary reference intake" for phosphorus: a critical perspective. J. Am. Coll. Nutr., 20, 271-278

Schmelzle, T. and Hall, M.N. (2000): TOR, a central controller of cell growth. Cell, 103, 253-262.

Segawa, H., Yamanaka, S., Ito, M., Kuwahata, M., Shono, M., Yamamoto, T. and Miyamoto, K. (2005): Internalization of renal type IIc Na-Pi cotransporter in response to a high-phosphate diet. Am. J. Physiol. Renal Physiol., 288, F587-596.

Seo, S., Fujita, H., Nakano, A., Kang, M., Duarte, A. and Kume, T. (2006): The forkhead transcription factors, Foxc1 and Foxc2, are required for arterial specification and lymphatic sprouting during vascular development. Dev. Biol., 294, 458-470.

Shah, B., Krishnarao, G. and Draper, H. (1967): The relationship of $\mathrm{Ca}$ and $\mathrm{P}$ nutrition during adult life and osteoporosis in aged mice. J. Nutr., 92, 30-42.

Shimada, T., Kakitani, M., Yamazaki, Y., Hasegawa, H., Takeuchi, Y., Fujita, T., Fukumoto, S., Tomizuka, K. and Yamashita, T. (2004): Targeted ablation of Fgf23 demonstrates an essential physiological role of FGF23 in phosphate and vitamin D metabolism. J. Clin. Invest., 113, 561-568.

Sie, T.L., Draper, H.H. and Bell, R.R. (1974): Hypocalcemia, hyperparathyroidism and bone resorption in rats induced by dietary phosphate. J. Nut., 104, 1195-1201.

Smith, O. and Davis, C. (1962): Potato quality XIII. Preventing after-cooking discoloration in oil blanched French fries. Am. J. Potato Res., 39, 45-56.

Sullivan, C., Sayre, S.S., Leon, J.B., Machekano, R., Love, T.E., Porter, D., Marbury, M. and Sehgal, A.R. (2009): Effect of food additives on hyperphosphatemia among patients with end-stage renal disease: a randomized controlled trial. JAMA, 301, 629-635.

Takeda, E., Taketani, Y., Morita, K., Tatsumi, S., Katai, K., Nii, T., Yamamoto, H. and Miyamoto, K. (2000): Molecular mechanisms of mammalian inorganic phosphate homeostasis. Adv. Enzyme Regul., 40, 285-302.

Takeda, E., Yamamoto, H., Nashiki, K., Sato, T., Arai, H. and Taketani, Y. (2004): Inorganic phosphate homeostasis and the role of dietary phosphorus. J. Cell Mol. Med., 8, 191-200.

Tenenhouse, H.S. (2005): Regulation of phosphorus homeostasis by the type iia na/phosphate cotransporter. Annu. Rev. Nutr., 25, 197-214.

Traebert, M., Hattenhauer, O., Murer, H., Kaissling, B. and Biber, J. (1999): Expression of type II Na-Picotransporter in alveolar type II cells. Am. J. Physiol., 277, L868-873.

Uribarri, J. (2006): Phosphorus homeostasis in normal health and in chronic kidney disease patients with special emphasis on dietary phosphorus intake. Semin. Dial., 20, 295-301.

Wang, C., Li, Y., Shi, L., Ren, J., Patti, M., Wang, T., de Oliveira,
J.R., Sobrido, M.J., Quintáns, B., Baquero, M., Cui, X., Zhang, X.Y., Wang, L., Xu, H., Wang, J., Yao, J., Dai, X., Liu, J., Zhang, L., Ma, H., Gao, Y., Ma, X., Feng, S., Liu, M., Wang, Q.K., Forster, I.C., Zhang, X. and Liu, J.Y. (2012): Mutations in SLC20A2 link familial idiopathic basal ganglia calcification with phosphate homeostasis. Nat. Genet., 44, 254-256.

Wang, L., Fraley, C.D., Faridi, J., Kornberg, A. and Roth, R.A. (2003): Inorganic polyphosphate stimulates mammalian TOR, a kinase involved in the proliferation of mammary cancer cells. Proc. Natl. Acad. Sci. USA, 100, 11249-11254.

Weiner, M.L., Salminen, W.F., Larson, P.R., Barter, R.A., Kranetz, J.L. and Simon, G.S. (2001): Toxicological review of inorganic phosphates. Food Chem. Toxicol., 39, 759-786.

White, K.E., Evans, W.E., O'Riordan, J.L., Speer, M.C., Econs, M.J., Lorenz-Depiereux, B., Grabowski, M., Meitinger, T. and Strom, T.M. (2000): Autosomal dominant hypophosphataemic rickets is associated with mutations in FGF23. Nature Genetics, 26, 345-348.

Wulaningsih, W., Michaelsson, K., Garmo, H., Hammar, N., Jungner, I., Walldius, G., Holmberg, L. and Van Hemelrijck, M. (2013): Inorganic phosphate and the risk of cancer in the Swedish AMORIS study. BMC Cancer, 13, 257.

Xu, C.X., Jin, H., Chung, Y.S., Shin, J.Y., Hwang, S.K., Kwon, J.T., Park, S.J., Lee, E.S., Minai-Tehrani, A., Chang, S.H., Woo, M.A., Noh, M.S. An, G.H., Lee, K.H. and Cho, M.H. (2009): Low dietary inorganic phosphate affects the lung growth of developing mice. J. Vet. Sci., 10, 105-113.

Xu, C.X., Jin, H., Lim, H.T., Ha, Y.C., Chae, C.H., An, G.H., Lee, K.H. and Cho, M. H. (2010): Low dietary inorganic phosphate stimulates lung tumorigenesis through altering protein translation and cell cycle in K-ras(LA1) mice. Nutr. Cancer, 62, 525-532.

Xu, C.X., Jin, H., Lim, H.T., Kim, J.E., Shin, J.Y., Lee, E.S., Chung, Y.S., Lee, Y.S., Beck, G.Jr., Lee, K.H. and Cho M.H. (2008): High dietary inorganic phosphate enhances cap-dependent protein translation, cell-cycle progression, and angiogenesis in the livers of young mice. Am. J. Physiol. Gastrointest. Liver Physiol., 295, G654-663.

Xu, H., Bai, L., Collins, J.F. and Ghishan, F.K. (1999): Molecular cloning, functional characterization, tissue distribution, and chromosomal localization of a human, small intestinal sodiumphosphate (Na+-Pi) transporter (SLC34A2). Genomics, 62, 281284.

Xu, H., Bai, L., Collins, J.F. and Ghishan, F.K. (2002): Age-dependent regulation of rat intestinal type IIb sodium-phosphate cotransporter by $1,25-(\mathrm{OH})(2)$ vitamin $\mathrm{D}(3)$. Am. J. Physiol. Cell Physiol., 282, C487-493.

Xu, Y., Yeung, C.H., Setiawan, I., Avram, C., Biber, J., Wagenfeld, A., Lang, F. and Cooper, T.G. (2003): Sodium-inorganic phosphate cotransporter NaPi-IIb in the epididymis and its potential role in male fertility studied in a transgenic mouse model. Biol. Reprod., 69, 1135-1141.

Yeung, C.H., Sonnenberg-Riethmacher, E. and Cooper, T.G. (1999): Infertile spermatozoa of c-ros tyrosine kinase receptor knockout mice show flagellar angulation and maturational defects in cell volume regulatory mechanisms. Biol. Reprod., 61, 1062-1069.

Yin, B.W., Kiyamova, R., Chua, R., Caballero, O.L., Gout, I., Gryshkova, V., Bhaskaran, N., Souchelnytskyi, S., Hellman, U., Filonenko, V., Jungbluth, A.A., Odunsi, K., Lloyd, K.O., Old, L.J. and Ritter, G. (2008): Monoclonal antibody MX35 detects the membrane transporter NaPi2b (SLC34A2) in human carcinomas. Cancer Immun., 8, 3 . 